vorhanden. Wird daher bei häufigerem Umkrystallisieren ein Glycerid-Schmelzpunkt über $69,5^{\circ}$ oder ein Schmelzpunkt der Fettsäuren über $64,5^{\circ}$ gefunden, so beweisen derartige Werte, unabhängig von der Höhe der Schmelzpunkts-Differenz, die Gegenwart von Talgen. - Vergl. jedoch auch hierzu oben unter 7. und S. 607.

\title{
Nachtrag.
}

Nach einigen vorläufigen Untersuchungen scheint das Prinzip dieses neuen Verfahrens auch zum $\mathrm{Nachweise} \mathrm{von} \mathrm{Schweinefett} \mathrm{in} \mathrm{Butterfett} \mathrm{und} \mathrm{Gänse-}$ fett verwendbar zu sein. Wir hoffen, darüber bald berichten zu können.

Der Vorsitzende: Ich danke Herrn Professor Bömer für seine interessanten Mitteilungen. Ich frage, ob einer der Herren das Wort dazu wünscht. Das ist nicht der Fall.

Dann tritt jetzt die Frühstückspause ein; wir werden die Verhandlungen um 1/21 Uhr wieder beginnen. Wie Sie aus der Tagesordnung ersehen, erwartet uns noch ein äußerst wichtiger Vortrag des Herrn Dr. Ha upt. Bei der Bedeutung dieses Vortrages bitte ich Sie, möglichst vollzählig wieder zu erscheinen.

(Frühstückspause von $11^{1 / 2}-1^{1 / 4}$ Uhr).

Der Vorsitzende: Ich eröffne die Sitzung hiermit und bitte Herrn Dr. Haupt, uns nunmehr seinen Vortrag zu halten.

\section{Die Beseitigung der Industrieabwässer und die Untersuchung der Kläranlagenabflüsse.}

\author{
Von Dr. H. Haupt in Bautzen.
}

Die Abwasserfrage gewinnt in Deutschland andauernd an stetig wachsender Bedeutung: Die zunehmende Industrialisierung unseres Landes, das Wachstum der Städte, die Einführung der Kanalisation, selbst in den kleineren Industrieortschaften, bringen eine immer größere Verschmutzung der öffentlichen Vorfluter mit sich. Mit der Reinhaltung der öffentlichen Wasserläufe verknüpfen sich aber nicht nur sehr wichtige Interessen der Hygiene, des Heimatschutzes und der Ästhetik, sondet $\mathrm{n}$ es sind vor allen Dingen wirtschaftliche Fragen, die hier eine grobe Rolle spielen. Ist das Wasser der Vorfluter durch eine zu große Verschmutzung dem Allgemeingebrauch für landwirtschaftliche Zwecke, wie zur Viehtränke, zum Wiesenwässern usw. entzogen, so bleibt dies nicht ohne wirtschaftliche Folgen für die Anlieger.

Noch weit schwerwiegender sind meist die Nachteile der Verschmutzung, wenn das Wasser auch für industrielle Zwecke, als Kesselspeisewasser oder gar als Betriebswasser, nicht mehr verwendet werden kann. Die anliegende Industrie sucht sich, soweit sie auf reines Wasser angewiesen ist, in solchen Fällen durch Anlage ausgedehnter Betriebswasserreinigungsanlagen zu helfen. Sowohl deren Errichtung wie ihr Betrieb erfordern aber erhebliche Opfer und der Zweck wird bei sehr verschmutzten Vorflutern auch dann meist noch nicht einmal vollständig erreicht. Die Folge ist, dass man sich in industriellen Gebieten zur Wasserversorgung vielfach des Grund- 
wassers bedient, sodaß häufig eine allzu starke Inanspruchnahme desselben stattfindet. Dieses Grundwasser aber ist auch vielfach nicht ohne weiteres als Betriebswasser geeignet. Es muß oft erst enteisent werden, was gleichfalls mit laufenden Kosten verbunden ist, ganz abgesehen von den erheblichen Kosten, welche durch die Herstellung der Wassergewinnungsanlagen verursacht werden. Eine zu starke Benutzung der Grundwasserschätze hat ausserdem häufig in umfangreichen Gebieten ein Absinken des Grundwasserspiegels zur Folge, wodurch oft Land- und Forstwirtsehaft geschädigt werden.

Die Verunreinigungszone pflegt sich bei den Flüssen oft auf weite Entfernungen hin zu erstrecken, sodaß häufig die Anlieger weithin unterhalb der direkten Verunreinigungsquelle noch wirtschaftlich geschädigt werden, und daß die fernere Entwickelung der Industrie an derartigen Vorflutern unterbunden oder mindestens arg beschränkt wird. Die meisten Bundesstaaten haben in den letzten Jahren durch gesetzliche Maßnahmen den mannigfachen wirtschaftlichen Schäden, welche mit der Wasserverunreinigung verbunden sind, Rechnung getragen, und haben die Erlaubnis für die Einleitung verschmutzter Abwässer an gewisse Bedingungen und Einschränkungen geknüpft. Am häufigsten wird nunmehr als Bedingung für die Erlaubnis zur Wasserbenutzung die Forderung einer dem jeweiligen Stande der Technik entsprechenden durchgreifenden Reinigung der Abwässer gestellt. Die verhältnismäßig hohen einmaligen und die fortlaufenden Kosten, welche die Abwasserreinigung den beteiligten Siädten und Gemeinden, sowie dem einzelnen Industriellen auferlegt, bringen es andererseits mit sich, daß fast allenthalben von beteiligter Seite zunächst ein lebhafter Widerspruch gegen solche Anforderungen der Verwaltungsbehörden sich geltend macht. Es kommt hinzu, daß die Abwasserreinigungstechnik ein noch in der Entwickelung begriffenes Wissensgebiet darstellt, in welehem man erst im Laufe der letzten beiden Jahrzehnte zu grundlegenden festen Anschauungen gekommen ist.

Da die Kenntnis der Grundsätze, nach welchen sich die Reinigung der bäuslichen und gewerblichen Abwässer vollzieht, durchaus noch nicht Allgemeingut ist, so hat es nicht an schweren Milgriffen in bezug auf die Konstruktion und den Umfang der Kläranlagen gefehlt. Aber selbst, wo die letzteren zweckdienlich hergestellt worden sind, hat man oft der so überaus wichtigen Frage der Schlammbeseitigung nicht die erforderliche Aufmerksamkeit zugewandt, sodaß der Betrieb sich unrationell und zu teuer gestaltet. Man hat oft teure Betonarbeiten ausführen lassen an Stellen, wo billige Absitzteiche denselben Dienst geleistet hätten. Vor allem finden sich in den Industrieorten meist zahlreiche Einzelkläranlagen, von denen jede in den Raumabmessungen beschränkt und wenig wirksam ist, statt einer einzigen gemeinsamen Kläranlage am Ortsende.

Jedenfalls erscheinen die Abwasserfragen in unserem Lande wichtig genug, um von allen den Stellen, bei denen man die hierfür nötige Sachkenntnis voraussetzen darf, eifrig studiert und mit der Zeit einer befriedigenden Lösung zugeführt zu werden.

Während man die Frage der Beseitigung städtischer Abwässer jetzt als so gut wie gelöst ansprechen darf, bietet die Reinigung einiger Arten von Industrieabwässern noch immer mehr oder minder große Schwierigkeiten. Durch ausgedehnte und sorgsam bediente Anlagen kann man zwar der Theorie nach auch fast alle Arten von Industrieabwässern genügend reinigen, aber die Unkosten stehen hier bisweilen in keinem rechten Verhältnis zu dem erzielten Vorteil und zu der Leistungsfähigkeit der betreffenden Betriebe. Es ist wohl selbstverständlich, daB, wo nur immer irgend möglich, 
und wo nicht größere Interessen dem entgegen stehen, entscheidender Wert darauf gelegt werden muß, daß die industriellen Unternehmungen nicht mit zu großen Opfern für die Reinigung ihrer Ábwässer belastet werden, damit ihre wirtschaftliche Stellung im Wettkampf gegenüber dem Ausland und gegenüber der günstiger - etwa an größeren Vorflutern - gelegenen Industrie, aufrecht erhalten bleibt.

Andererseits ist der bisherige Zustand, dab vielfach äuBerst mangelhafte oder gar keine Kläranlagen für die Industrieabwässer bestehen, und daf da, wo solche vorhanden sind, die Bedienung oft vieles, ja alles, zu wünschen übrig läßt, auf die Dauer im Interesse einer vernünftigen Wasserwirtschaftspolitik nicht haltbar. Die Bekämpfung der fortschreitenden FluBverunreinigung muB vielmehr mit Ausdauer von allen dazu berufenen Stellen aufgenommen und von allen Einsichtigen im Staate unterstützt werden, denn sie ist eine Sache, welche das Allgemeinwohl angeht.

Es wird notwendig sein, daß sich auch die Industrie sehneller die Fortschritte, welche von der Abwasserklärungstechnik gemacht worden sind, zunutze macht und mehr Verständnis als bisher den Abwasserfragen entgegenbringt. Die Aufgabe der Regierung wird es andererseits sein, dafür zu sorgen, daß durch Prüfung der Kläranlagenprojekte von unabhängiger und wirklich sachverständiger Seite, den beteiligten Kreisen unnötige Aufwendungen für die Errichtung unzweckmäßiger oder unnötig teurer Kläranlagen erspart bleiben. Letztere werden durch selbstsüchtige und oft nicht genügend erfahrene Unternehmerfirmen häufig den Industriellen angeboten.

Eine wesentliche Kostenersparnis wird in den allermeisten Fällen der genos senschaftliche Zusammenschlu. B benachbarter Großindustrien oder von Gemeinden und Industrie zwecks gemeinsamer Klärung ihrer Abwässer bedeuten. Wo immer möglich, sollten die Gemeinden selbst die nötigen Kläranlagen beschaffen, um die häuslichen Abwässer mit den industriellen Abwässern gemeinsam zu reinigen, wobei die Industrie, entsprechend dem Gehalt ihrer Abwässer, zu den Kosten des Kläranlagebaues und des Reinigungsverfahrens beranzuziehen wäre. Da, wo die Menge des industriellen Abwassers im Verhältnis zu der des häuslichen Abwassers zurückbleibt, wird die gemeinsame Klärung zumeist auf keinerlei größere Schwierigkeiten stoßen. Wo aber die Eigenart bestimmter Industrieabwässer ein besonderes Verfahren verlangt, genügt oft schon eine Vorklärung derselben an Ort und Stelle, und man kann die Nachreinigung getrost mit den häuslichen Abwässern vornehmen. Auch so wird eine Entlastung der Industrie von den ihr obliegenden aber ihr immerhin fernerstehenden Aufgaben der Abwasserreinigung erreicht, für welche die letztere gern den auf sie entfallenden Anteil der Kosten übernehmen wird. In sebr vielen Fällen ist also mit der Errichtung einer städtischen Zentralkläranlage auch die zweckmäßäige Beseitigung der industriellen Abwässer gewährleistet. Daß aber die Frage der Reinigung der städtischen Abwässer jetzt als gelöst gelten kann, wurde bereits erwähnt.

Bei dieser engen Verknüpfung der häuslichen und der industriellen Abwasser beseitigung mögen ganz kurz die Anforderungen an städtische Kläranlagen hier gestreift werden:

Je nach der Wasserführung und der sonstigen Beschaffenheit der Vorfluter, welche die gereinigten Abwässer aufzunehmen haben, wird man mehr oder minder hohe Anforderungen an den Reinheitsgrad der Abwässer und somit an die Leistungen des Reinigungsverfahrens stellen müssen. Bei kleinen Vorflutern oder bei im Verhältnis zur Wasserführung des Flusses sehr erbeblichen Abwassermengen wird das biologische Reinigungsverfahren in erster Linie in Frage kommen. Ob man der biologischen 
Reinigung auf Rieselland den Vorzug zu geben hat, oder ob die künstliche biologische Reinigung auf Tropfkörpern bezw. Füllkörpern zur Anwendung kommen soll, muß nach den örtlichen Verhältnissen beurteilt werden. In jedem Falle wird es einer Vorreinigung bedürfen, für welche entweder langgestreckte Absitzbecken (bezw. Faulkammern) oder Klärbrunnen - welche gewöhnlich nach dem System der EmscherBrunnen oder doch diesen ähnlich ausgebildet sind - in Frage kommen. Durch die Emscher-Brunnen, Kremer-Brunnen usw. wird eine Trennung des noch frischen Abwassers von der Hauptmenge der abscheidbaren Schwebestoffe bewirkt, und man kann vielfach das so von Schlamm befreite Wasser trotz seines noch hohen Gehaltes an kolloidal verteilten Schwebestoffen unmittelbar auf biologischen Tropfkörpern weiter behandeln.

Hat man es mit wasserreicheren Vorflutern zu tun, so wird die biologische Nachreinigung häufig sich erübrigen. Es wird dann genügen, das Abwasser lediglich mechanisch vorzureinigen; sei es, dah man durch Emscher-Brunnen den Schlamm entfernt und das friscbe schlammfreie Abwasser dem Selbstreinigungsvorgang im Vorfluter überläßt, oder sei es, daß man Absitzbecken oder Absitzteiche hierfür verwendet. Nicht unerwähnt dürfen für die Reinigung häuslicher $\mathrm{Abwässer,} \mathrm{denen} \mathrm{keinerlei} \mathrm{giftige}$ Stoffe beigemischt sind, die aussichtsreichen Vorschläge von $\mathrm{H}$ o fer-München bleiben. Die Reinigung spielt sich nach ihm in Fischteichen ab. Das Abwasser wird meist mit Reinwasser vermischt eingeführt und durch die intensiven biologisehen Vorgänge im Wasser und im Schlamm solcher Teiche erfolgt die Selbstreinigung. In den Fällen, wo besonders große Vorfluter in Betracht kommen, wird man sich endlich damit begnügen dürfen, aus den städtischen Abwässern lediglich durch Sandfang und Rechenvorrichtung bezw. Siebscheibe, die gröberen Sink- und Schwebestoffe heraus zu fangen, und dem Selbstreinigungsvorgang den weiteren Abbau der organischen Substanzen überlassen dürfen.

Wie bereits erwähnt worden ist, bieten gewisse Industrieabwässer selbst nach Verdünnung durch große Mengen von Hausabwässern Schwierigkeiten bei der gemeinsamen Reinigung. Meist handelt es sich hierbei um Abwässer, durch die sowohl die Selbstreinigung in den öffentlichen Vorflutern ungünstig beeinflußt wird, als auch die biologischen Vorgänge in den Kläranlagen, weil sie für Mikroorganismen giftige Stoffe enthalten. In diesen Fällen hat sich das Reinigungsverfahren genau der Eigenart des betreffenden Abwassers anzupassen, und man hat sein Bestreben vor allem auf die Unschädlichmachung dieser Giftstoffe zu richten. Überwiegt die Menge derartiger für die Selbstreinigung schädlicher Industrieabwässer, so können dieselben erst nach entsprechender Vorklärung an Ort und Stelle in die genossenschaftliche Kläranlage aufgenommen werden, oder sie müssen überhaupt für sich gereinigt werden.

Aber auch aus in der Örtlichkeit oder den Geländeverhältnissen begründeten Rücksichten wird es bisweilen unmöglicb sein, das Abwasser der Industrie auf dem für diese selbst, wie für das Allgemeinwohl bestem Wege, nämlich gemeinsam mit den städtischen Haus- und Fäkalabwässern unschädlich zu machen. Eine Menge großer gewerblicher Betriebe wird übrig bleiben, welche durch ihre vereinzelte Lage oder durch die Eigenart ibrer Abwässer gezwungen sind, eigene Kläranlagen zu unterhalten. Wir haben außerdem in Deutschland noch einen langen Weg vor uns, bis alle Industriegebiete dem rühmlichen Beispiel der Emscher-Genossenschaft gefolgt und zur gemeinsamen großzügigen Behandlung der Abwasserfrage geschritten sind. Bis dahin wird man sich vielfach noch mit den alten, wenig wirksamen 
industriellen Einzelkläranlagen behelfen und sich damit begnügen müssen, wenigstens durch sorgsamen Betrieb dieser Kläranlagen den bestmöglichsten Klärerfolg zu erzielen, um so den durch die Flubverunreinigung bewirkten Schaden, wenn auch nicht zu vermeiden, - so doch auf ein tunlichst geringes Maß herabzusetzen.

Eine regelmäßige, ohne Härten ausgeübte Beaufsichtigung des Betriebes sowohl der größeren genossenschaftlichen wie der Einzelkläranlagen, wird sicher am wirksamsten diese Bestrebungen unterstützen können, und erscheint für die Zukunft als eine unabweishare Notwendigkeit. Größere Kläranlagen sollten alle Monate durch orientierende chemische Untersuchungen auf ihren Wirkungswert, kleinere wenigstens jährlich einmal geprüft werden.

Nach allen bisherigen Erfahrungen versagen nämlich auch die besten Kläranlagen bald ihren Dienst, wenn nicht von seiten des Staates eine ständige Aufsicht und Kontrolle ausgeübt wird. In England, wo man - gedrängt durch das Anwachsen der Industrie und die mit der Flußverunreinigung verbundenen schweren Schäden der Abwasserfrage bereits seit vier Jahrzehnten intensive Aufmerksamkeit gezollt hat, bestehen besondere Flußaufsichtsämter, welchen die Kontrolle über die Flüsse und Kläranlagen obliegt. Bei uns wird die Aufsicht in den einzelnen Bundesstaaten durch die verschiedensten Organe: Verwaltungsbehörden, Wasserbauämter, Gewerbeinspektionen und Bezirksärzte bezw. Kreisärzte usw. ausgeübt.

Die neue Wassergesetzgebung in den einzelnen Bundesstaaten hat fast überall den Verwaltungsbehörden den entscheidenden Einflup auch auf die Abwasserfrage gesichert. Für die Ausübung der Kontrolle bedürfen diese aber natürlich sachverständiger Organe und als solche werden - soweit nicht rein sanitäre oder bautechnische Interessen im Vordergrund stehen - in erster Linie die Regierungschemiker berufen sein. Iaufende, leicht ausfübrbare technische Vorprüfungen und die Entuahme der Proben aber wird man dem geschulten Kläranlagenpersonal überlassen können. Viele Bundesstaaten besitzen zwar bereits Zentralstellen für derartige hygienische und gewerbepolizeiliche Untersuchungen, aber die Ausdehnung des Reiches und die schnelle Veränderung, welcher Abwasserproben häufig beim Transport ausgesetzt sind, bringen es ganz natürlich mit sich, daß erstinstanzlich die Kontrolle und die Beaufsichtigung des Zustandes der Flüsse den örtlichen und provinzialen Organen übertragen wird und daß die Zentralstelle nur in schwierigeren Fällen und in allen grundlegenden Fragen gehört wird. Es mag daher durchaus nicht überflüssig erscheinen, hier etwas näber auf die Beurteilung der Wirkungsweise von Kläranlagen einzugehen, um so mehr, da trotz der vielen Veröffentlichungen auf diesem Gebiete noch immer bäufig eine falsche Auffassung über die Art, wie derartige Untersuchungen aufzufassen sind, besteht.

Nicht selten werden die Analysen schematisch nach dem Gange, wie er bei Trink- und Mineralwasseranalysen üblich ist, durchgeführt. Es werden manche für die Erreichung des Zweckes völlig unnötigen Bestimmungen ausgeführt, welche Zeitverlust veranlassen und die Analyse verteuern, ohne auf den Kernpunkt der Sache einzugehen. Ferner herrscht oft Unklarheit darüber, welche Ansprüche man je nach der Art der Kläranlage an das gereinigte Wasser zu stellen berechtigt ist. So wurde z. B. nach einer mir vertraulich gewordenen Mitteilung erst kürzlich einer deutschen Großstadt eine Auflage gemacht, nach welcher durch eine gut wirkende mechanische Kläranlage außer den ungelösten Stoffen auch $30-40 \%$ der gelösten organischen Stoffe beseitigt werden sollen! 
Es ist wohl selbstverständlich, daß man von einer lediglich mechanisch wirkenden Anlage nur die Beseitigung der absitzbaren ${ }^{1}$ ) Sink- und Schwebestoffe erwarten darf, während die kolloidal verteilten Schwebestoffe - falls es sich nicht um einen Faulraum handelt, in dem chemische Umsetzungen stattfinden - ebensowenig durch derartige Anlagen beeinflubt werden können, wie die gelösten organischen Verunreinigungen.

Je nach der Durchflubgeschwindigkeit und je nach der Konstruktion der mechanisch wirkenden Kläranlage, wird die mechanische Vorreinigung eine mehr oder minder weitgehende sein. So gestatten nach den mir freundlichst zugestellten Betriebsergebnissen aus den mechanischen Kläranlagen der Emscher-Genossenschaft beispielsweise die Emscher-Brunnen in der Praxis durchschnittlich eine Zurückhaltung der absitzbaren Schwebestoffe von $95-99 \%$, während die Abnahme an GesamtSchwebestoffen im jahrelangen Durchschnitt keinesfalls unter $70 \%$ betrug. Nur wenig ungünstiger sind die Ergebnisse bei der Anwendung der langgestreckten Becken, wie sie Steuernage l-Köln verwendet, oder bei der Anwendung von Sandfang und Rechen mit nachgeschalteten langen Absitzbecken. Mit diesen erreichte man nach Till mans in Frankfurt bei 5-10 mm Durchflußgeschwindigkeit einen Kläreffekt von rund 90\% der ausscheidbaren Stoffe. Die Prüfung der Wirkung einer lediglich mechanisch wirkenden Kläranlage wird sich also in erster Linie auf die Bestimmung der noch vorhandenen absitzbaren Schwebestoffe - das sind die sich innerhalb zweier Stunden beim Stehen freiwillig ausscheidenden Suspensa - erstrecken. AuBerdem wird man der Beschaffenheit des Abflußwassers, ob frisch, angefault, oder in starker Fäulnis begriffen, würdigende Beachtung zu schenken haben, und sich von dem Zustand der Stickstofferbindungen im Abwasser durch die Bestimmung der Salpetersäure, der Nitrate und des Ammonialss sowie unter Umständen des organisch gebundenen Ammoniaks unterrichten. Diese Bestimmungen werden von Bedeutung für die Beurteilung der weiteren Selbstreinigung im Vorfluter sein, denn es ist nicht gleichgültig, ob das Abwasser in frischem oder in stark angefaultem Zustande in den Vorfluter gelangt, da seine weitere Verarbeitung und die mit ihr verbundene Sauerstoffabnahme im Flub hiervon sowie von dem Verdünnungsgrade und der Stromgeschwindigkeit. abhängig ist.

In den Fällen, wo eine weitergehende Reinigung des Abwassers gefordert werden muß, wo also eine natürliche oder künstliche biologische Nachreinigung stattfindet, wird es sich stets darum handeln, als Endergebnis ein Abwasser zu erhalten, welches nicht mehr fäulnisfähig ist. Die Prüfung auf Fäulnisfähigkeit wird hier im Vordergrund des Interesses stehen. Außer ihr wird fast allgemein noch die Feststellung des Gehaltes an organischer Substanz, sowie die der Stickstoffverbindungen ausgeführt. In einem biologisch gut gereinigten Abwasser mul bereits eine weitgehende Nitrifikation stattgefunden haben.

Für die Beurteilung des Zustandes von Flüssen in bezug auf den Verlauf der Selbstreinigung und das weitere Aufnahmevermögen für Abwässer ist bekanntlich die Bestimmung des im Wasser gelösten Sauerstoffs (Sauerstoffdefizits) und der Sauerstoffzehrung nach der bekannten Winkler'schen Methode von größter Wichtigkeit. Bei der Prüfung der Wirksamkeit von Tropfkörpern usw. kann natürlich diese Bestimmung gleichfalls recht wertvoll sein, sie wird aber nicht zu den für gewöhnlich und regelmäBig auszuführenden Feststellungen gehören. Bei den noch stark verschmutzten Abflüssen aus Faulräumen oder Klärbecken und -Brunnen wird man sich

1) Vgl. Spilln er, Gesundheitsingenieur 1910, 33, Nr. 39. 
der modifizierten Methode zu bedienen haben, wenn man den Sauerstoffgehalt des Wassers bestimmen will.

Bei industriellen Kläranlagen wird der Erfolg der Reinigung unter anderem auch darnach za bemessen sein, daß bestimmte für die Selbstreinigung im Vorfluter unerwünschte Stoffe aus den Abwässern entfernt worden sind, z. B. freie Säuren aus denen von Beizereien, Messingblechfabriken, Schwefelkiesgruben, Drahtziehereien, Nickelblechfabriken und anderen Betrieben; freie Alkalien aus den Abwässern von Sodafabriken und Lumpenkochereien; Cyan- und Rhodanverbindungen, sowie Teerprodukte aus den Abwässern von Gasanstalten, Cyankalifabriken und ähnlichen Betrieben; schweflige Säure und organische Stoffe aus den Abwässern von Sulfitcellulosefabriken usw. Kurz, die Untersuchungen haben sich in diesen Fällen der Figenart des betreffenden Betriebsabwassers anzupassen und den Zweek des Klärverfahrens im Auge zu haben.

Da ständig die Zusammensetzung der Abflüsse schwankt, kommt es ganz allgemein bei der Prüfung des Wirkungswertes von Kläranlagen vor allem auf eine richtige Probenentnahme an. So wählt beispielsweise die Emscher-Genossenschaft bei der Prüfung ihrer Anlagen die Tagesstunden, in denen das Abwasser erfahrungsgemäß die größte Verschmutzung zeigt. Zur Prüfung gelangen dann Mischproben, die aus einzelnen Proben hergestellt sind, welche man in Zwischenräumen von je 15 Minuten entnommen hat. Gleichzeitig wird die Menge des Abwassers, welches die Kläranlagen durchfließt, mittels Flügelradmessung oder durch Schwimmermessung kontrolliert. - Bei vielen industriellen Betrieben ist die Konzentration des Abwassers sehr schwankend. Bei Leinen- und Baumwollgarnbleichereien, Lumpenkochereien, Sulfitcellulosefabriken, Braunpappenfabriken usw. flief̧t z. B. zu den Zeiten, wo die Kocherlaugen abgelassen werden, ein viel gehaltreicheres Wasser ab als sonst. Dies ist bei der Probenentnahme zu berücksichtigen.

Für die Feststellung des Wirkungswertes von biologischen Kläranlagen oder von mechanischen Vorreinigungsanlagen genügen für gewöhnlich die im folgenden übersichtlich zusammengestellten Bestimmungen, deren Ausführung ich der Einheitlichkeit halber allgemein empfehlen möchte. Es handelt sich zumeist um Verfahren, die seitens erfahrener Spezialinstitute auf diesem Gebiete, z. B. der Kgl. Landesanstalt für Wasserhygiene zu Berlin, des chemischen Laboratoriums der Emscher-Genossenschaft, des Instituts von Geheimrat König in Münster und anderwärts angewendet werden. Bei größeren Anlagen empfehlen sich regelmäßige technische Betriebskontrollen.

Seitens der Emscher-Genossenschaft werden z. B. für die Prüfung ihrer zum größten Teil nur mechanisch wirkenden Kläranlagen (Emscher-Brunnen) täglich dureh das Personal technische Untersuchungen ausgeführt, bei welchen die Menge des Troekenwetterabflusses durch dreimalige Pegelablesungen bestimmt wird, während bei Regenwetter noch weit häufiger Messungen vorgenommen werden. Ebenso werden dreimal täglich Luft- und Abwassertemperatur (letztere im $\mathrm{Zu}$ - und Ablauf) abgelesen. Auf Schwefelwasserstoff wird einmal täglich der Zu- und Ablauf des Abwassers nach Aufkochen von $100 \mathrm{ccm}$ Abwasser mittels Bleipapiers geprüft. Je nach dem Schwärzungsgrade wird auf die Menge des Schwefelwasserstoffgases als "nicht vorhanden", "in Spuren vorhanden" oder "vorhanden" geschlossen. Die Menge der innerhalb zweier Stunden absitzbaren Schwebestoffe wird in den von Spillner angegebenen $50 \mathrm{~cm}$ hohen, $500 \mathrm{ccm}$ fassenden Absitzgläsern gleichfalls täglich gemessen und zwar wird genau nach der bekannten Durchflu@zeit des Abwassers auch aus dem Abfluß eine zweite Probe entnommen und in derselben Weise geprüft. 
Nicht überall werden sich diese Vorprüfungen regelmäßig ausführen lassen, weil vielfach kein genügend geschultes Personal hierfür zur Verfügung steht, bei den monatlich oder $1 / 4-j a ̈ h r l i c h$ von seiten des Chemikers auszuführenden Prüfungen sollten aber stets wenigstens folgende Bestimmungen ausgeführt werden:

1. Durchsichtigkeit: Man gibt die Dicke der Wasserschicht in $\mathrm{cm}$ an, durch welche bei zerstreutem Tageslicht die Snellen'sche Schriftprobe No. 1 noch eben lesbar erscheint. Man bedient sich mit Vorteil eines mit plan-parallelem Glasboden versehenen $30 \mathrm{~cm}$ hohen Zylinders, der unten mit Hahnablauf versehen ist (Lieferant: Altmann-Berlin). Das Wasser läßt man solange ablaufen, bis die Schichthöhe die Erkennung der Schriftprobe gestattet.

2. Reaktion: Prüfung in der üblichen Weise mittels Lackmuspapiers.

3. Geruchsprobe: Je nach dem Ausfall der Geruchs- und der Fäulnisprobe wird das Wasser als „frisch", „erdig-modrig riechend“, „schal“, oder ,angefauli" bezeichnet.

4. Fäulnisprobe: Die Probe wird in geschlossener, fast ganz gefüllter Flasche bei Zimmertemperatur aufbewahrt. Jeden Tag wird eine Menge von $50 \mathrm{ccm}$ aus der Flasche entnommen, aufgekocht und hierbei in der üblichen Weise mit Bleiacetat geprüft. Nach Angabe von $\mathrm{Bach}$ - Essen ist diese Kochprobe weit schärfer, als die früher übliche Bleipapierprobe auf kaltem Wege. Es empfieblt sich außerdem die verbesserte Methylenblauprobe nach Weldert-Spitta für die Prüfung auf Fäulnisfähigkeit in den Fällen heranzuziehen, wo sich diese nicht von vorneherein durch den Geruch zu erkennen gibt. Bisweilen wird man auch die Fäulnisprobe außerdem mit Verdünnungen von 1-2 Teilen Flubwasser anstellen, um so einen Einblick in das Verhalten des geklärten Abwassers im Vorfluter zu gewinnen.

5. Schlammgehalt (absetzbare Schwebestoffe): Man ermittelt, wie viel ccm Schlamm sich bei zweistündigem Stehen aus 1 Liter Abwasser freiwillig abscheiden. Die Bestimmung kann in den von Spillner angegebenen Absitzgläsern erfolgen. Ich benutze für diesen Zweck mit Ausguß versehene Spitzgläser (nach Eckerlin) von $100 \mathrm{ccm}$ Inhalt, welche in einem Holzfuß stehen. Die unteren $10 \mathrm{ccm}$ des Spitzglases, welche gewissermaßen seinen hohlen Stiel bilden, sind graduiert. Der Schlamm rutscht an den steilen Wänden des Spitzglases gut herab, sodaß man leicht sein Volumen ablesen kann.

6. Ungelöste Stoffe: Neben der Bestimmung des Volumens der absitzbaren Schwebestoffe wird fast stets auch die Bestimmung der ungelösten Stoffe in der üblichen Weise durch Filtration und Sammeln des Niederschlages auf einem gewogenen Filter vorgenommen. Mit Vorteil kann man sich hierbei auch der Gooch-Tiegel aus Platin bedienen. Durch Veraschung wird die Menge der mineralischen und der organischen ungelösten Stoffe bestimmt. Letztere stellen bekanntlich die für die Vorfluter unangenehmsten Substanzen dar. Für die regelmäßige und orientierende Betriebskontrolle von mechanischen Vorkläranlagen (Absitzhecken, Emscher-Brunnen usw.) mögen die eben genannten Bestimmungen völlig genügen.

Will man sich ein genaueres Bild von der Beschaffenheit des Abwassers verschaffen, so sind noch folgende Bestimmungen empfehlenswert:

7. Abdampfrückstand: Die Bestimmung erfolgt in der üblichen Weise.

8. Glührückstand: Die Bestimmung erfolgt in der üblichen Weise. 
9. Glühverlust: Die Bestimmung erfolgt in der üblichen Weise.

10. Oxydierbarkeit (Bestimmung des Sauerstoffverbrauches in saurer Lösung nach Kubel-Tiemann): Die Bedeutung der Bestimmung des Sauerstoffoder Permanganatverbrauches für die Beurteilung des Reinheitsgrades von Abwässern ist zwar vielfach bestritten worden, weil eine ganze Anzahl nicht wegzuleugnender Mängel derselben anhaften. Sie ist meines Erachtens aber doch immer unentbehrlich, weil sie wenigstens gute Vergleichswerte für den Gebalt an organischer Substanz innerhalb einer bestimmten Serie von Wässern gibt und weil auch aus der Abnahme der prozentualen Menge dieser organischen Substanz innerhalb der Kläranlage gute Schlüsse in bezug auf den Reinigungseffekt der einzelnen Stufen gezogen werden können. Nötig ist es nur, die Prüfung stets tunlichst bald vorzunehmen und sich vor Augen zu halten, daß sowohl hochmolekulare Körper (aus den Abwässern von chemischen Fabriken usw.) oft nicht ganz vom Permanganat innerhalb der üblichen 10 Minuten währenden Kochdauer angegriffen werden, und andererseits, daß gewisse bei der chemisch-mechanischen Vorklärung häufig zugesetzte Chemikalien, wie Eisenoxydulsalze usw. gleichfalls einen Sauerstoffverbrauch bedingen und so das Resultat stark beeinflussen können. Trägt man den Nebenumständen Rechnung, so wird man aber doch mit dieser Methode meist recht annehmbare Vergleichswerte erhalten. Es ist empfehlenswert, die erhaltenen Werte nicht als "organische Substanz" oder als "Permanganatverbrauch", sondern als Sauerstoffverbrauch in $\mathrm{mg}$ auszudrücken, um so eine Übereinstimmung mit der englischen und französischen Abwasserliteratur herbeizuführen.

Von größter Wichtigkeit für die Beurteilung der Fäulnisfähigkeit des Abwassers ist ferner die Bestimmung der Stickstoffverbindungen.

11. Nitrate: Nitrate werden entweder kolorimetrisch mit Hilfe der Bruzinoder Diphenylaminreaktion oder quantitativ nach der allerdings nur Annäherungswerte gebenden, aber in der Hand des Geübten doch brauchbaren Indigomethode bestimmt.

12. Nitrite: Die salpetrigsauren Salze werden kolorimetrisch am besten mittels Metaphenylendiaminsulfats bestimmt.

13. Ammoniak: Der Nachweis erfolgt in der üblichen Weise mittels Nessler's Reagens. Die Anwesenheit von Ammoniak im Abwasser ist ein Zeichen des noch nicht beendeten Oxydationsprozesses, während umgekehrt die Anwesenheit reichlicher Mengen von Salpetersäure bei häuslichen und bei vielen industriellen $A b$ wässern die gelungene Reinigung anzeigt.

14. Organischer Stickstoff: Die Menge des organischen Stickstoffes bildet bekanntlich gleichfalls einen Maßstab für die Fäulnisfähigkeit des Abwassers. Die Bestimmung erfolgt in der üblichen Weise nach $\mathrm{Kjeldahl.}$

15. Gebundenes Chlor: Die Bestimmung gibt bei gemischten Abwässern einen Anhalt über die Menge der häuslichen Abwässer, falls nicht gleichzeitig Bleichereiabwässer in Frage kommen. Kochsalz ist aber auch in vielen Grubenwässern vorhanden. Die Bestimmung erfolgt in der üblichen Weise.

Die vorstehend geschilderten Untersuchungen werden stets genügen, um die Reinigungswirkung von Kläranlagen zu prüfen, in welchen Hausabwässer, Fäkalabwüsser oder diese beiden Abwasserarten gemischt mit mäßigen Mengen von Industrieabwässern gereinigt werden.

Bei der Untersuchung der unvermischten gereinigten Industrieabwässer muß 
die Prüfung vornehmlich auf diejenigen Stoffe ausgedehnt werden, deren ganze oder teilweise Entfernung durch die Abwasserreinigung bezweckt wird. So enthalten z. B. die Abwässer aus Schlachthöfen, Brauereien, Brennereien, Stärke- und Zuckerfabriken, aus Molkereien und Gelatinefabriken namentlich große Mengen organischer, stickstoffhaltiger Verunreinigungen. Die Prüfung hat sich also vormehmlich auf die Feststellung des noch vorhandenen Gehaltes an diesen Stoffen zu erstrecken. Auberdem gehen viele der genannten Abwasserarten bereits in der Kläranlage in saure Gärung über und enthalten dann freie Buttersäure, Milchsäure, Essigsäure usw. Die Feststellung des Gehaltes an freier Säure hat hier in der üblichen Weise zu erfolgen.

Nicht minder reich an organischer Substanz und dabei gleichzeitig auch reich an Fetten sind manche Abwässer der Textilindustrie, so namentlich die aus Wollwäschereien und Appreturanstalten. Hier wird eine Bestimmung des Rohfettes (Ätherextraktes) sowie in manchen Fällen die der Seifen im Abwasser am Platze sein. Der Abdampfrückstand wird vorgetrocknet und alsdann mit Seesand verrieben und im Soxleth'schen Apparat 3-4 Stunden lang entfettet. Allerdings gehen die flüchtigen Fettsäuren bei dieser Bestimmungsmethode während des Trockenprozesses verloren, meist kann man diese aber vernachlässigen.

Bei den Abwässern der Gasanstalten sowie bei den Abwässern großer Sauggasanlagen (Skrubberwässer), bei den Cyankalifabriken und bei den Kokoreien kommen bäufig erhebliche Mengen von Cyanverbindungen, namentlich Rbodanverbindungen, Teerprodukte, Phenole, Kresole usw. vor, und verleihen denselben giftige Eigenschaften für eine etwaige biologisehe Nachreinigung. Die eben genannten Stoffe wirken bekanntlich abtötend auf die für die biologische Reinigung sowie für die Selbstreinigung im Vorfluter unumgänglich notwendigen Mikroorganismen. Die quantitative Bestimmung der Cyanverbindungen erfolgt durch Destillation nach Zugabe von Natriumbicarbonat und Auffangen des Destillates in mit Salpetersäure angesäuerter $1 / 10 \mathrm{~N}$.-Silbernitratlösung, worauf in bekannter Weise verfahren wird. Die Bestimmung des Phenols kann nach der von Korn ausgearbeiteten Methode erfolgen.

Auf eine Reihe weiterer, für niedere Organismen giftiger Stoffe ist in den Abwässern größerer Gerbereien zu fahnden, so auf Arsen, auf Schwefelnatrium und auf Chromverbindungen. Der Nachweis erfolgt in der bekannten Weise. Anorganische Verunreinigungen enthalten endlich auch die Abwässer aus Bergwerken aller Art, aus Metallwarenfabriken, Nickelblechfabriken, Galvanisieranstalten usw. Es handelt sich hier häufig sowohl um den Nachweis der freien Säure, wie um den der betreffenden Metallsalze. Der Nachweis bietet in keinem Fall Schwierigkeiten.

Für den Nachweis der freien schwefligen Săure im Abwasser der Sulfitcellulosefabriken wird das auch in der Nabrungsmittelchemie übliche Verfahren angewendet.

Es mögen noch besondere Fälle vorkommen, bei denen auf diesen oder jenen Stoff im Abwasser gefahndet werden muß. Jedenfalls muß die Untersuchung stets sinngemäli erfolgen und auf die Eigenart der Betriebe, aus welchen das Abwasser stammt, Rücksicht genommen werden. Man behalte bei der Auswahl der Methoden stets den Zweck im Auge, den die Analyse des Abwassers haben soll, nämlich sich ein zutreffendes Bild von dem Verschmutzungsgrade und der etwa noch vorhandenen Schädlichkeit des Abwassers zu machen. Jede überflüssige Bestimmung, wie man sie leider noch so häufig antrifft, bedeutet nur einen unnötigen Aufwand an Zeit 
und erschwert lediglich die Übersicht des Ergebnisses. So ist z. B. die Bestimmung des Kieselsäuregehaltes, des Kalk- und Magnesiagehaltes, wie der gebundenen Schwefelsäure usw. für die Beurteilung der Abflüsse aus Kläranlagen meist völlig bedentungslos.

In den allermeisten Fällen werden die oben näher beschriebenen Untersuchungsmethoden für die regelmäßige Überwachung der Kläranlagen genügen. Wo laufende Kontrollen größerer Kläranlagen ausgeführt werden, kann man die Ergebnisse in graphischer Weise durch Kurven und Tafeln veranschaulichen ( $\operatorname{m}$ hoff). Man gewinnt so einen Überblick über die durchschnittliche Leistung der Anlagen, frei von Zufälligkeiten einzelner Probeentnahmen.

M. H.! Nachdem ich Ihnen so die Methoden geschildert habe, die heutzutage am meisten für die Untersuchung der Abwässer herangezogen werden, mag es von Interesse sein, zu hören, welche Anforderungen man denn an den Reinheitsgrad der geklärten Abwässer zu stellen hat. Der Chemiker wird als Berater der Verwaltungsbehörde in zweifacher Hinsicht in die Lage kommen, derartige Anforderungen vorzuschlagen. Einmal, wenn es sich bei Neukonzessionierungen von industriellen Unternehmungen oder Erweiterungen derselben bei Einführung städtischer Schleusen usw. darum handelt, den Allgemeingebrauch für die Unterlieger zu erhalten, und andererseits, wenn Abflüsse aus bereits bestehenden Kläranlagen daraufhin beurteilt werden sollen, $o b$ sie berechtigten Ansprüchen genügen.

Der erstere Fall soll hier nicht näher erörtert werden, da er dem beutigen Thema ferner liegt. Es genügt, darauf hinzuweisen, daß die Ansprüche an den Umfang der Kläranlagen und das Maß der zu fordernden Reinheit der Abwässer unter sorgamster Würdigung vor allem der biologischen Verhältnisse des Vorfluters, ferner des zu schützenden, noch ausgeübten Allgemeingebrauches und seiner wirtschaftlichen Bedeutung - der etwa in Zukunft zu erwartenden stärkeren Benutzung des Flußwassers für diesen oder jenen Zweck - der Erheblichkeit und der wirtschaftlichen und sanitären Bedeutung der begehrten Wasserbenutzung, formuliert werden müssen. Stets mub man sich der schweren Verantwortung sowohl bei der Befürwortung eines derartigen Gesuches um Einführung von verunreinigten Abwässern, wie bei der Ablehnung desselben bewubt sein, da es sich zumeist um tief in das Wirtschaftsleben einzelner, oft auch in das der Allgemeinheit einschneidende Dinge handelt.

Hinsichtlich der an lediglich mechanisch wirkende Kläranlagen $\mathrm{zu}$ stellenden Ansprüche ist bereits betont worden, daß die vollkommensten von ihnen die absitzbaren Schwebestoffe fast völlig, mindestens aber bis zu $90 \%$ aus dem Abwasser zurückhalten, vorausgesetzt, daß der Schlamm regelmäfig entfernt wird, so daß nicht etwa eine ungenügende Verminderung der Durchflußgeschwindigkeit in ihnen eintritt, indem ein zu erheblicher Teil des nutzbaren Raumes vom Schlamm eingenommen wird. Bei den Absitzanlagen für gewerbliche Abwässer, namentlich bei denen für Papierfabriken, Holzschleifereien, Erzpochwerke, Kohlenwäschereien und ähnliche Betriebe, bei denen gewaltige Mengen von Abwässern mechanisch vorgeklärt werden sollen, begegnet man häufig einer viel zu geringen Raumbemessung für den Absitzvorgang. Die Durehflußgeschwindigkeit erleidet nicht die nötige Herabminderung und der Kläreffekt in bezug auf die absitzbaren Schwebestoffe beträgt nur $30 \%$ derselben und weniger. Hier ist Vergrößerung und zweckdienliche technische Gestaltung der Vorklärung anzustreben. Wo gemauerte Becken oder Klärbrunnen zu kostspielig sind und die örtlichen Um- 
stände es gestatten, können Klärteiche, die freilich regelmäßig ausgeschlammt werden müssen, zum Ziele führen.

Bisweilen empfiehlt es sich die Wirkung mechanischer Vorklärungen durch Zusätze von Chemikalien in ganz geringer Menge zu unterstützen, da manche Arten von Abwässern weniger absitzbare Schwebestoffe als vielmehr kolloidal gelöste Körper enthalten. Man erreicht durch die Zusätze (Kalk, Eisenalaun, Aluminiumsulfat und ähnliche Zuschläge kommen in Frage) bei derartigen Wässern eine ganze oder teilweise Zerstörung des kolloidalen Zustandes und erhält so eine weit bessere Reinigung als beim bloben Absitzverfahren. Durch die groben Erfolge der biologischen Nachreinigung, welche ohne weiteres auch die kolloidal verteilten und gleichzeitig die gelösten organischen Verunreinigungen fast restlos aus dem Abwasser entfernt, ist in Deutschland das chemische Fällungsverfahren etwas in den Hintergrund geraten, während man es in England vielfach zur Unterstützung der mechanischen Vorreinigung beibehalten hat. Ohne Zweifel hat dasselbe seine Berechtigung auch bei uns, zwar nicht als selbstständiges Reinigungsverfahren an sich, wohl aber in Verbindung mit dem Absitzverfahren und - wo nötig - mit der biologiseben Nachreinigung. Das gilt ganz besonders für gewisse Arten von Industrieabwässern, die so viel kolloidale Stoffe enthalten, daß ihre bloße mechanische Vorklärung bei der Einleitung in mittelgroße Vorfluter nicht genügt, sondern durch die erwähnte teilweise Fällung unterstützt werden muß. Dieselben Abwässer müssen bei kleineren Vorflutern bis zur Fäulnisunfähigkeit nachgereinigt werden und setzen der Nachreinigung auf biologischem Wege ohne voraufgegangene Fällung erheblichen Widerstand entgegen, weil die Menge der in ihnen enthaltenen gelösten und scheinbar gelösten (kolloidalen) organischen Substanz so übergroß und so besonderer Art ist (z. B. bei konzentrierten Seifenabwässern), daß leicht eine Überlastung der kontinuierlich betriebenen Tropf- oder intermittierend betriebenen Füllkörper eintritt, die zu deren schneller Verschlammung und Unwirksamkeit führt. Hierhin sind zu zählen unter Umständen die Abflüsse der Schlachthöfe, falls keine Verdünnung durch häusliche, weniger gehaltreiche Abwässer erfolgt, ferner die stark seifen- und stärkeoder leimbaltigen Wässer aus Appretur und Waschanstalten, die Abwässer der Lumpenkochereien (Hadernhalbstoffwerke), der Wollwäschereien, die konzentrierten Laugen der Leinengarn- und Baumwollbleichereien, die Abwässer der Filztuchfabriken, die mancher Färbereien und besonders der mit Schwefelfärbereien verbundenen Baumwollabfallspinnereien usw., kurz alle Arten von Abwässern, die eine ungewöhnlich hohe Konzentration aufweisen. Die Herabsetzung dieses hohen Gehaltes an gelösten und an Schwebestoffen auf andere Weise, z. B. durch einen Ausfaulungsprozess würde durch die Art der sonst noch in ihnen enthaltenen Stoffe, (z. B. Gehalt an Schwefelnatrium oder Lauge usw.) Schwierigkeiten bieten; bisweilen sind die letzteren auch in der groben Menge des täglich anfallenden Abwassers zu suchen, dessen längere Aufspeicherung für einen Ausfaulungsprozess zu große Räume benötigen würde. Bei solchen gehaltreichen Industrieabwässern mit einem Gesamtrückstand von oft $3000-$ 7000 , ja bis $14000 \mathrm{mg}$ im Liter und einem Gehalt an gelösten und kolloidalen organischen Substanzen von 2-4000 $\mathrm{l} / \mathrm{mg}$ ist dringend zur chemischen Vorklärung da zu raten, wo nicht genügend andere $A b$ ässer zur Verdünnung vor der biologischen Nachreinigung zur Verfügung stehen. Dass eine derartige chemische Vorbehandlung für Abwässer, die bestimmte giftige oder doch für den Vorfluter gefährliche Chemikalien, z. B. Arsenverbindungen, Schwefelnatrium, Rhodansalze, Phenolkörper, freie 
Säuren, freie Alkalien usw. enthalten, nicht zu umgehen ist, bedarf keiner besonderen Erwähnung. Ebensowenig bedarf es in diesem Kreise besonderer Ausführungen darüber, daß man von einer chemischen Vorkläranlage die nahezu vollständige oder vollständige Beseitigung derjenigen Körper fordern darf, gegen die sich das Verfahren rishtet, daß aber andererseits jeder Überschuß des Fällungsmittels nach Möglichkeit vermieden werden muß.

Da, wo der Zusatz der Chemikalien - für deren gute Durchmischung mit dem Abwasser durch zweckentsprechende Rührwerke oder sonstige mechanisch betätigte Vorrichtungen stets Sorge zu tragen ist, - lediglich zur Verminderung des Gehaltes an kolloidaler und gelöster organischer Substanz erfolgt, kann mau nach dem Absitzvorgang oft eine Herabsetzung derselben um 80-99\% beobachten und mithin auch verlangen, während bei denselben Abwässern die rein mechanische Vorklärung nur 20\% Abnahme der organischen Stoffe (gemessen am Sauerstoffverbrauch) und weniger ergab.

Man wolle mich jedoch nicht mißverstehen: Ich bin weit entfernt, für das alte chemische Fällungsverfahren, bei welchem die Frage der Schlammbeseitigung die Klärung so außerordentlich erschwert, im allgemeinen einzutreten, nur bei den vorerwähnten Abwasserarten erscheint es mir bei sorgsamer Dosierung der Zuschläge und gleichzeitiger Lösung der Schlammfrage empfehlenswert.

$\mathrm{Ob}$ die Notwendigkeit für eine solche weitergehende und daher kostspieligere Klärung vorliegt, kann immer nur nach den biologischen Verhältnissen des Vorfluters beurteilt werden, die ihrerseits durch Wasserführung und Stromgeschwindigkeit desselben wesentlich beeinflubt werden. Es sind ferner der Nutzungszweck des Vorfluters und die etwa möglichen gesundheitlichen Nachteile, die beim Unterbleiben der Reinigung $\mathrm{zu}$ erwarten sind, für die Beurteilung von Bedeutung.

In allen den Fällen, wo eine Nachreinigung dureh künstliche (durch Oxydationskörper) oder natürliche biologische Behandlung (durch Rieselfelder, intermittierende Bodenfiltration oder endlich durch die Selbstreinigungsvorgänge im Vorfluter selbst) erfolgt, wird man berechtigt sein, die höchsten Anforderungen an das Reinwasser zu stellen. Wie eingangs erwähnt wurde, ist das Endziel der biologischen Reinigung die Beseitigung der Fäulnisfähigkeit der Abwässer. Es genügt, dieses Ziel erreicht zu haben, und nur in vereinzelten Ausnahmefällen wird man darüber hinaus eine Beseitigung der etwa noch vorhandenen Spuren eines Farbstoffs oder der aus den Oxydationskörpern ausgespülten Stoffe fordern dürfen. Die Abflüsse der Tropfkörper gehören in biologischer Hinsicht meist der $\beta$ mesosaproben Zone an (System Kolkwitz-Marson) und in sehr wasserarmen Vorflutern kann es daher noch zur Verkrautung und Verpilzung nach Einleitung reichlicher Mengen gut gereinigter Tropfkörperabflüsse kommen, nie aber zu offensiven Erscheinungen. Die Nitrate und Nitrite und die Reste organischer Substanz in den Abläufen regen das Wachstum der höheren Wasserpflanzen und die Vermehrung der Mikroorganismen kräftig an (König u. Grobe-Bohle). Eine Nachreinigung etwa auf einem einstufigen intermittierend betriebenen Füllkörper oder durch Sandfiltration kann daher in ganz besonders gelagerten Fälen noch notwendig sein, ist aber keinesfalls allgemein zu fordern.

Bei Industrieabwässern wird hier und da ein sehr hoher Reinigungsgrad erstrebt und auch mit Hilfe ausgedehnter Oxydationsfilter da erreicht, wo eine Wiederverwendung des gereinigten Abwassers im Betriebe statifinden soll. So werden z. B. 
Färbereiabwässer gemischt mit Appreturabwässern mit Hilfe des Preibisch'schen Verfahrens oder des Brendler'schen Grabenfilterverfahrens - das als eine Verbindung der intermittierenden Bodenfiltration mit dem Oxydationsverfahren anzusehen ist bis zur völligen Farblosigkeit und bis zu einem Sauerstoffverbrauch von nur ungefähr $6 \mathrm{mg}$ für 1 Liter gereinigt. Doch wird man im allgemeinen nicht so hohe Anforderungen an die gereinigten Abwässer stellen dürfen.

Es erübrigt noch, auf Einzelheiten in der Reinigung der industriellen Abwässer kurz hier einzugehen, besonders auf die Fälle, wo durch ihre Eigenart eine besondere Behandlung am Platze ist. - Vorausgesetzt wird hiebei stets, daß die betreffenden Abwässer mangels einer genossenschaftlichen Kläranlage für sich allein behandelt werden müssen.

Hinsichtlich der Einteilung der gewerblichen Abwässer kann ich mich an die anerkannte Autorität auf dem Gebiete der Abwasserfragen, unseren hochverehrten langjährigen Vorsitzenden, Geheimrat König-Münster, anlehnen, hinsichtlich der Verfahren auf Bretschneider, Thumm, Schiele sowie auf eigene Erfahrungen verweisen.

Die erste Gruppe umfaßt Abwässer mit hohem Gehalt an organischer stickstoffhaltiger Substanz. Ihrer Zusammensetzung wie ihrer Wirkung auf die Biologie der Gewässer nach, ähneln sie den Hausabwässern, nur daß die Industrieabwässer meist viel gehaltreicher sind als diese.

Hierhin gehören unter anderem die Abwässer aus Brauereien, Brennereien, Stärke- und Zuckerfabriken, Molkereien und Margarinefabriken, Gelatine- und Leimfabriken, auch mauche Arten von Abwässern aus Gerbereien und Lederfabriken, von Schlachthöfen usw.

Diese Abwässer können ähnlich behandelt werden wie Hausabwässer und ohne Schwierigkeit gemeinsam mit solchen gereinigt werden.

Bierbrauereien: Nur in große Vorfluter können sie ungeklärt eingeleitet werden. Die Abwassermenge ist nach cbm Ausstoß zu berechnen, und zwar beträgt sie das drei- bis sechsfache der erzeugten Biermenge. Großbrauereien, bei denen die

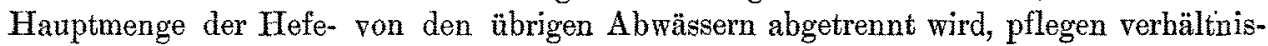
mäßing reineres Abwasser zu entlassen als Kleinbetriebe.

Die schlimmsten Abwässer sind die Gerstenweichwässer, welche nur im Herbst and Winter bei denjenigen Brauereien, die selbst mälzen, entstehen. Alle Brauereiabwässer neigen zur raschen sauren Gärung, wodurch die gewöhnliche biologische Reinigung scheitert. Wegen der vielen Kolloide bewähren sich Emscher-Brunnen nicht, besonders nicht in der Vorreinigung. Die beste Reinigungsmethode, welche zugleich ausgezeichnete Futtererträge liefert, ist die Landberieselung nach vorheriger Abstumpfung der freien Säure durch Kalkmilch. Wo sie untunlich erscheint, muß die Nachbehandlung auf Fülkörpern erfolgen, wo genügend Wasser vorhanden, verdünnt man das vorgeklärte neutrale Brauereiabwasser zweckmäßig vor Aufleitung auf die Tropfkörper.

Brennereien und Preßhefefabriken sollten wie Brauereien mit ihren Abwässern verfahren.

Stärkefabriken: Die Abwässer pflegen die Umgebung sehr zu belästigen, da sie leicht in saure Gärung und Fäulnis übergehen. Die Reinigung erfolgt wie bei Brauereiabwasser. Die Verunreinigungen des Abwassers aus Kartoffelstärkefabriken 
ist schwächer als die der übrigen Stärkefabriken. Für die Nachreinigung verdienen ausgedehnte Füllkörper vor den Tropfkörpern den Vorzug.

Zuckerfabriken: Hier fallen in dem Rübenwaschwasser neben organischen Stoffen große Mengen erdigen Schlammes an, außerdem die gehaltreichen Schnitzelpressabwässer und Knochenkohlenwaschwässer. Die Reinigung von den erdigen Bestandteilen erfolgt in ausgedehnten Schlammabsitzteichen, deren Durchflußgeschwindigkeit 10 Sekunden-Millimeter nicht überschreiten sollte. Rübenschwänze und Pülpe müssen durch die hierfür vorhandenen modernen maschinellen Einrichtungen vorher zurückgehalten werden. Für die Nachreinigung der stärker verunreinigten Anteile der Abwässer kommen Gradierwerke, in denen Sphaerotilus und Leptomitus die teilweise Aufzehrung der organischen Stoffe bewirken, oder $2 \mathrm{~m}$ hohe Tropfkörper in Betracht. Bei diesen ist auf $1 \mathrm{cbm}$ Abwasser $1 \mathrm{qm}$ Körperoberfläche zu rechnen. Die gesonderte Behandlung der gehaltreichen Diffusions- und Presswässer ist empfehlenswert.

Molkereien und Margarinefabriken: Die Abtrennung der Molken, welche in ländlichen Käsereien häufig statt anderweitig nutzbar gemacht zu werden, in das Abwasser gelangen, und dieses unnötigerweise noch gehaltreicher machen, ist zu fordern, zumal, da diese an Schweine verfüttert werden können. Das Spülen der Betriebsräume nach Beendigung der Arbeitszeit mit Eisensulfatlösung ist empfehlenswert. Viele Betriebe sind nicht leistungsfähig genug, um die Kosten für die Errichtung von Tropfkörpern aufbringen zu können. Die Landbehandlung nach vorheriger Fällung des Abwassers mit Kalkmilch und Zurückhaltung der Kalkseifen usw. hat sich wiederholt glänzend bewährt. Fettarme Molkereiabwässer können ohne chemizche Vorklärung nach französischen Autoren ohne weiteres auf besonders ausgedehnten Tropfkörpern oder Füllkörpern erfolgreich behandelt werden. Ich sah in der Praxis hierbei stets Miberfolge und rate, die Vorbehandlung da nicht zu unterlassen, wo die örtlichen Verbältnisse die Landberieselung verbieten, und man auf die Nachreinigung durch Tropfkörper angewiesen ist. In städtischen Molkereien, deren Abwässer dem Kanalnetz zugeführt werden, ist dennoch die Abstumpfung durch Kalk empfeblenswert, da sonst leicht die Kanäle von den oft stark sauren Wässern angegriffen werden.

Konservenfabriken: Die Abwässer werden wie Molkereiabwässer behandelt.

Gerbereien und Lederfabriken: Die Abwasserbeseitigung macht bei großen Betrieben, die im Platze beengt, an kleinen Vorflutern liegen, besondere Schwierigkeiten.

Vor jedem, wie auch immer gearteten Reinigungsverfahren mul das den Kalkäschern meist zugesetzte Schwefelnatrium und das Chrom aus dem Abwasser durch Eisensalzzusatz niedergeschlagen werden. Wo genügend Land zur Verrieselung zur Verfügung steht, leitet man die sehr verschiedenen im Betrieb anfallenden Abwasserarten zusammen, wobei meist bereits eine ergiebige Fällung stattfindet, und verrieselt nach dem Absetzen. Recht häufiges Entschlammen des Sammelbeekens ist nötig, da dessen Inhalt sonst in intensive Fäulnis übergeht. Bei beschränkterem Raum muß man zur künstlichen biologischen Reinigung nach vorheriger Entfernung des Übermaßes an freiem Ätzkalk durch Luftberieselung und nach Fällung der gemischten Abwässer durch Eisenalaun schreiten. Nach den noch nicht abgeschlossenen bisberigen Erfahrungen haben sich Füllkörper den Tropfkörpern hierbei überlegen gezeigt; doch sind die bisherigen Erfolge im allgemeinen überhaupt keine guten.

Schlachthöfe: Schlachthofabwasser mul, bevor es einer städtischen Klär- 
anlage zugeführt wird, in besonderen Faulbecken vorbehandelt werden, damit Fett und Haare in die dicke sich bildende Schwimmdecke gehen. Der noch immer sehr gehaltreiche Abfluß aus diesen Becken wird dann zu dem häuslichen Rohwasser geleitet. Vereinzelt liegende Schlachthöfe klären am besten durch chemische Fällung mit Hilfe von etwas Kalk und Eisen bezw. Thonerdesulfat. In Klärtürmen oder Becken muf das Abwasser vom Niederschlag befreit und nach genügender Verdünnung biologisch nachbehandelt werden. Für die Fettgewinnung haben sich, wie bei anderen besonders fettreichen Abwässern, so auch hier Kremer-Apparate bewährt.

Die zweite Gruppe umfaßt gewerbliche Abwässer, die zwar gleich. falls reich an organischen Stoffen, aber verhältnismäbig arm an Stickstoffverbindungen sind. Hierher gehören viele Abwässer der Textilindustrie, die der Wollwäschereien, Spinnereien, Filztuchfabriken, Appreturanstalten, Bleichereien, Färbereien, Zeugdruckereien, Holzschleifereien, Hadernhalbstoffwerke, Papierfabriken, Federreinigungsanstalten, Sulfitcellulosefabriken. Die Abwässer in dieser Gruppe enthalten bisweilen besondere Stoffe, welche eine gleichartige oder ähnliche Behandlung wie bei den Hausabwässern und denen der ersten Gruppe nicht zulassen.

Die Wollwäschereiabwässer gehören wohl in bezug auf ibren Einflub auf die Flüsse zu den seblimmsten Abwässern, die es überhaupt gibt. Die ersten Waschwässer, welche viel organische Kalisalze enthalten, können eingedampft und auf Pottasche verarbeitet werden, die - weil eisenfrei - besonders in den Feinglashütten Aufnahme findet. $\mathrm{Da}$ derartige Nebenbetriebe aber nur höchst ungern von der Industrie angelegt werden, gelangen auch diese besonders gehaltreichen Waschwässer meist auf dem Wege durch die Kläranlagen in die Vorfluter. Aus den stark seifenund fetthaltigen weiteren Waschwässern wird alsdann mittels Schwefelsäure der fettreiche Schlamm abgeschieden, heiß gepreßt und das abgeschiedene Fett auf Leuchtgas verarbeitet. An diesem decken aber die Fabriken vielfach ihren ganzen Bedarf, wenn sie die Wässer eines Monats verwenden. Es besteht daher meist wenig Neigung, das Verfahren dauernd auszuüben. Statt mit Schwefelsäure können die Abwässer auch mit Kalk und Eisenalaun gefällt werden. Für die weitere Reinigung ist die Landbehandlung oder - nach Schoof s-lüttich - die auf zweistufigen Oxydationskörpern zu empfehlen.

Appreturanstalten, Tuchfabriken, Filztuchfabriken. Die Abwässer enthalten viel Seife und Spinnöl, oft auch reichliche Mengen Stärke und Dextrin von der Appretur, alles in emulsionsartigem Zustand. Hier ist ein ähnliches Fällungsverfahren wie bei Wollwäschereiabwässern durch Tonerdesalze - oft auch nur durch Kalkmilch - am Platze. Die Wiedergewinnung des Fettes ist nicht immer lohnend. Gute Erfolge kann man kei von sachkundiger Hand durchgeführter intermittierender Bodenfiltration hier sehen, sodaß die Drainwässer sogar in den Betrieb zurückgenommen werden können. Voraussetzung ist aber eine Vorreinigung mittels Fällung, sonst verschlicken sie den Boden schnell. Die Verfahren von Preibisch und Brendler eignen sich für Färbereiabwässer, die durch viel Spülwässer verdünnt sind, sogar ohne Vorbehandlung durch Chemikalien.

Färbereien und Chemische Waschanstalten. Soweit die Abwässer dieser Betriebe sich nicht nach dem eben beschriebenen Verfahren reinigen lassen - wo also ganz konzentrierte Abwässer von Schwefelfärbereien, Baumwollabfallspinnereien und ähnlichen Betrieben vorliegen - müssen sie sehr sorgsam oft durch doppelte Fällung 
vorgereinigt werden, namentlich mul das Schwefelnatrium quantitativ aus ihnen entfernt werden, weil es im Vorfluter zur Bildung von Schwefeleisenschlamm Veranlassung gibt und indirekt zum Sauerstoffmangel beiträgt. Rideal schlägt zur Entfärbung in der Vorreinigung Zusatz von Hypochlorit vor und nachherige Belüftung auf Tropfkörpern. Man kann gleich gute Erfolge bei der Nachreinigung auf Tropfkörpern wie auf Füllkörpern beobachten. Letztere sind rein physikalisch sogar dort wirksam, wo durch die Eigenart des Farbstoffs oder sonstiger Chemikalien Mikroorganismen innerhalb der Körper nicht aufkommen können.

Übrigens erfolgt durch die immer zunehmende Einführung der Apparatenfärbereien und die bessere Ausnutzung der Farbbäder allmählich ganz allgemein eine Besserung der Färbereiabwässer. Die $A$ bwässer von Indigofärbereien (Zeugdruckereien) sind an sich weit weniger gefährlich als die der übrigen Betriebe.

Bleichereien. Hier sind es nicht so sebr die chlorhaltigen Abwässer als vielmehr die alkalischen und an organischen Substanzen überreichen Kocherlaugen, die die Verpilzung der Vorfluter - nachdem das Chlor aufgehört hat, desinfizierend zu wirken - veranlassen. Die Wässer vom Absäuern reichen nicht zur Neutralisation dieser Laugen aus. Am besten werden die Laugen abgetrennt und für sich einem Fällungsverfahren unterworfen, darauf in Teichen der teilweisen Ausfaulung überlassen und mit den Spülwässern auf Tropfkörpern belüftet. Für die Verrieselung über Wiesen eignen sich die vorgereinigten und durch Spülwässer verdünnten, aber fast chlorfreien Abwässer sehr gut, nur müssen die Flächen so groß sein, daß internittierender Betrieb möglich ist. In einem Falle werden die Abwässer einer sehr großen Leinengarnbleicherei in großen Absitzteichen gespeichert, dann über Kaskaden aus Schlacken gescbickt, wieder in einen Absitzieich geleitet and noch zweimal belüftet. Der Erfolg ist einigermassen befriedigend. Bei einem vergleichenden Versuch mit der Belüftung des nur meshanisch vorgereinigten Abwassers einer Baumwollbleicherei einesteils durch Faschinen, andernteils durch Schlackentropfkörper erwiesen sich letztere als etwas wirksamer. Jedenfalls verschwindet das Chlor in Tropfkörpern bald, wenn die Konzentration des Abwassers nicht zu stark ist.

Strohgeflechtfabriken und Strohfärbereien geben äbnliche Abwässer ab wie Bleichereien und Färbereien, die ebenso zu behandeln sind.

Papierfabriken. Die Abwässer der Papierfabrikation und der mit dieser zusammenhängenden Betriebe bieten dadurch einer sachgemäben Reinigung so große Schwierigkeiten, daß sie in so großer Menge (von einer einzigen Fabrik täglich mehrere Tausend $\mathrm{cbm}$ ) anfallen. Das Hauptaugenmerk ist bei allen diesen Abwässern auf eine tunlichste Zurückhaltung wenigstens der Schwebestoffe zu richten, von denen im Liter Abwasser bei mittleren Vorflutern keinesfalls über $50 \mathrm{mg}$ (in bei $103^{\circ}$ getrocknetem Zustande) enthalten sein sollten. Eine weitere Zurückhaltung begegnet großen Schwierigkeiten.

In letzter Zeit hat die Stoffrückgewinnung - d. i. die technische Vervollkommnung der Apparatur zum Abfangen der Faserteilchen aus dem Abwasser zwecks ihrer sofortigen Wiederverwendung im Betrieb oder zur Pappenfabrikation - große Fortschritte gemacht. Ein Teil des Abwassers wird bei gut geleiteten Papierfabriken im Kreislauf geführt, der Rest in umfangreichen Klärbecken sedimentiert, und dann - was allerdings bisher selten in der Praxis beobachtet wurde - verrieselt. Jedenfalls ist grober Wert auf gute Zurückhaltung der Fasern und der Kaolins zu legen, da sonst die Vorfluter auf weite Strecken sich mit faulenden Sehlammbänken - 
oft noch weit unterhalb der Verunreinigungsstelle - bedecken. In Papierfabriken, die nur Halbstoffe verarbeiten und wenig bleichen, ist der Gehalt an gelösten organischen Verunreinigungen verhältnismäßig gering. Anders bei denen, die rohe Lumpen zu Halbstoff und weiter verarbeiten. Hier sind es wieder die schlimmen Kocherlaugen, welche den Abwasserfadenpilzen eine willkommene Nährstoffquelle bieten. Abtrennung dieser Laugen, die den Bleichereilaugen ähneln und gleiche Behandlung erfordern, ist sehr zu befürworten. Für Werke, die lediglich Hadern auf Halbstoff verarbeiten, und die dabei an zeitweilig wasserarmen Vorflutern liegen, bedarf es, wenn die unterliegende Industrie existenzfähig bleiben soll, recht umfänglicher Kläranlagen mit biologischer Nachreinigung. Ebenso werden die Streichereiabwässer der Chromo- und Buntpapierfabriken, welche viel Caseinleim usw. enthalten und leicht faulen, am besten für sich wie Molkereiabwässer behandelt.

Die Holzschleifereien und Pappenfabriken entlassen Wässer, die nicht immer so harmlos sind, als es auf den ersten Blick scheinen möchte, zumal da diese Werke fast durchweg hoch in den Gebirgen an den kleineren Vorflutern liegen. Auch sie möchten sich der modernen Stofffangeinrichtungen, wie Füllner-Filter, $\$$ ch midt'scher Trichter oder ähnlich konstruierter Vorrichtungen, deren es jetzt eine Menge gibt, zur Zurückhaltung ihrer Schwebestoffe mehr als bisher bedienen. Daß außerdem auch hier noch recht beträchtliche Mengen dem Holze entstammender gelöster Kohlehydrate und harzartiger Stoffe, die das Pilzwachstum begünstigen, in Lösung gehen - aber, weil die Zurückhaltung meist zu kostspielig werden würde, - meist stillschweigend geduldet werden, sei nebenher erwähnt. Weit schlimmere Abwässer als von der Weib- und Graupappenfabrikation fallen von der Braunpappenfabrikation an, da hier aus dem gedämpften Holz mehr Stoffe in Lösung gehen, die von den Abwasserpilzen als Nahrungsquelle ausgenutzt werden. Die Kochwässer sollten daher stets für sich verrieselt werden.

Strohstoffabriken. Es gibt in Deutschland nur noch sehr wenige Strobstoffabriken. Ihre Abwässer aber belästigen durch den eigenartigen Geruch stark die Anlieger, soweit es sich um kleinere Vorfluter handelt. Man ist dazu übergegangen, die Laugen im Vakuum einzudampfen und in Flammenöfen zur Wiedergewinnung der kaustischen Soda zu verbrennen. Dieser ProzeB ist zwar nicht lohnend für den Unternehmer, hält aber doch die allersehlimmsten Schädigungen vom Vorfluter fern.

Sulfitcellulosefabriken. Das Schmerzenskind jedes Abwasserfachmannes sind die Abwässer der Sulfitcelluloseindustrie. Es handelt sich ausschließlich um Großbetriebe mit Abwassermengen von beiläufig 5-20000 cbm in 24 Stunden und von einer durchschnittlichen Konzentration, die etwa die doppelte von normalem Hausabwasser ist. Alle bisherigen Maßnahmen sind an diesen Mengen gescheitert, da ihre richtige sachgemäße Klärung sofort den Betrieb unrentabel gestalten würde. So war z. B. bislang das Eindampfen der auch bier bei weitem gefährlichsten Kocherlaugen nur bei kleinen Betrieben unter besonders günstigen sonstigen Umständen wirtschaftlich durchführbar, so daß man diese Maßregel nicht empfehlen konnte. Es scheint aber neuerảings, daß man für das beim Eindampfen der Lauge entstehende Holzextrakt, nachdem man die bygroskopischen Salze aus ihm entfernt hat, eine Verwendung findet, die bescheidenen Nutzen verspricht, Daß die großen Massen dieses Extraktes, welche anfallen würden, wenn alle Cellulosefabriken ihre Kocherlaugen eindampfen sollten, nicht für Gerbereizwecke durchweg Verwendung finden können, liegt auf der Hand. Ebensowenig ist der Kosten wegen die Benutzung der 
Laugen als Staubbindemittel auf den Landstraßen durcbfübrbar. Die Abwasserfrage erscheint nicht gelöst bei der Alkoholgewinnung aus den Laugen, weil nur ein geringer Teil der in diesen enthaltenen Kohlehydrate vergärt, der Rest aber doch in die Flüsse gelangen würde. Auch die Verwendung des Extraktes als stickstoffsammelndes. Düngemittel hat wenig Aussicht auf praktischen Erfolg. Sollte auch die eingangs angedeutete Verwertung der Laugen, welche zurzeit noch erprobt wird, wieder sich als unmöglich erweisen, so bleibt nichts übrig, als auf die Vorsehläge zurückzugreifen, die Klason-Stockholm schon in London auf dem Siebenten Kongreß für angewandte Chemie gemacht hat. Nach ihm soll man die Kocherlaugen und ersten Waschwässer während der wasserarmen Zeit, wo keine hundertfache Verdünnung gewährleistet ist, gemeinsam in sehr großen Aufhaltebecken oder Teichen ansammeln, um sie bei höherem Wasserstande allmählich dem Flußwassser beizumischen. Jedenfalls darf die Frage der zweckdienlichen Beseitigung der Sulfitcelluloseabwässer zurzeit noch nicht als völlig gelöst angesprochen werden.

Eine dritte Gruppe von Abwässern enthält organische Stoffe, die nicht fäulnisfähig sind, sondern giftige Natur - wenigstens für die Mikroorganismen im Vorfluter - besitzen. Bei den beiden ersten Gruppen war das Bemühen bei der Reinigung darauf gerichtet, den organischen Stoffen ibre Fäulnisfähigkeit zu nehmen; bei der dritten Gruppe muß man versuchen, diese Stoffe selbst aus dem Abwasser zu entfernen. Die Sulfitcelluloseabwässer, welche vermöge ihres Gehaltes an organisch gebundener schwefliger Säure und an sulfosaurem Kalk nur nach großer Verdünnung im Vorfluter nachfaulen bezw, biologisch aufgearbeitet werden können, gehören eigentlich ebenso gut zu dieser Gruppe. Es gehören ferner hierher die Abwässer aus Gasanstalten, Sauggasanlagen, Ammoniakfabriken, Teerdestillationen, Farbenfabriken und Braunkohlenschwelereien. Ich kann mich in diesem Kreise von Fachgenossen bei der Besprechung dieser Abwässer kurz fassen. Ihre Reinigung muß nach den Regeln der chemischen Umsetzungen erfolgen. Man hat z. B. die giftigen Bestandteile, wie Cyanspuren, Rhodan, Schwefelammon durch Eisensalze zu fällen usw. Bisweilen lassen sich bei diesen Reinigungsverfahren noch verwertbare Produkte gewinnen, die wenigstens einen Teil der Klärkosten decken.

In der vierten Gruppe endlich kann man all die Abwässer zusammenfassen, welche anorganische Verunreinigungen in Gestalt von freien Säuren, freien Alkalien oder von Salzen enthalten. Es enthalten freie Säure die Abwässer aus vielen Bergwerksbetrieben, welche Sulfide fördern, die aus schwefelkieshaltigen Haldengesteinen usw., ferner aus Knopffabriken, Messingblechwerken, Galvanisieranstalten, Drahtziehereien, Nickelfabriken, Verzinkereien, Stanz- und Emailierwerken usw. Aus den alkalischen Haldenwässern, der Soda- und Pottaschefabriken gelangen freier Ätzkalk und Natriumsulfid in das Abwasser, endlich bei den Kaliwerken findet die bekannte Versalzung der Flüsse durch Chloride statt. Kochsalz ist als Auslaugungsprodukt des Salztons auch in vielen Steinkohlenwässern enthalten, ebenso gemeinsam mit Chlorcalcium und Chlormagnesium in den Salinenabwässern.

Es bedarf keiner Erwähnung, dass bei den erstgenannten Abwässern die Neutralisation anzustreben ist, während bei den Salzen bekanntlich alle Reinigungsbestrebungen versagen, und das Eindampfen, weil zu kostspielig, meist auch nicht gefordert werden kann.

Die Frage der Kaliabwässerbeseitigung, welche eben erst wieder von verschiedenen hervorragenden Fachleuten intensiv untersucht worden ist, ist eine Frage für sich, auf die hier nicht eingegangen werden soll. 
Bei den eingangs genannten industriellen Betrieben dieser Gruppe, z. B. Knopffabriken, Messinggießereien und ähnlichen läßt sich vorschreiben, daß mit der Unsitte, die gebeizten Gegenstände im fließenden Wasser zu spülen, gebrochen wird. Die ersten zwei Spülungen können vielmehr nacheinander in vom Wasser nicht durehflossenen Bottichen vorgenommen werden, deren sauer 'gewordener Inhalt, bevor er abgelassen wird, allabendlich zu neutralisieren ist. Es lassen sich dann aus dem sich absetzenden Schlamm noch wertvolle Metallreste wieder gewinnen.

M. H.! Ich bin am Ende meiner Ausführungen, die nicht in die Tiefe der einzelnen Fragen eindringen durften, da beabsichtigt war, lediglich einen Überblick über die zweckdienlichen Verfahren zur Beseitigung gewerblicher Abwässer, die bei der Nachprüfung solcher Abläufe üblichen Untersuchungsmethoden und die Anforderungen, die man - je nach Umfang der Klärverfahren - an die gereinigten Abwässer zu stellen berechtigt ist, zu geben, ohne auf Vollständigkeit Anspruch machen zu wollen. In der intensiveren Beschäftigung mit den Abwasserfragen winkt jedenfalls dem Chemiker noch ein reiches und interessantes Arbeitsgebiet, das ihm Freude machen kann, wenn er die Anfeindungen, denen der Abwasserfachmann von geschäftlich interessierter Seite leicht ausgesetzt ist, nicht fürchtet. Eine recht eingehende Kenntnis der Biologie der Gewässer und der Physiologie der niederen Pflanzen wird diese Tätigkeit besonders fruchtbringend gestalten helfen, denn Abwasserfragen dürfen niemals nach einseitigen Gesichtspunkten behandelt werden. Der Sachverständige muss vielmehr mit dem Gesamtzustand des Vorfluters in bezug auf seine Biologie usw. auf das genaueste vestraut sein.

Der Vorsitzende: Ich eröffne die Diskussion über den Vortrag des Herrn Dr. Haupt.

\section{Diskussion.}

Der Vorsitzende: Der Herr Vortragende hat einen für uns überaus wichtigen Gegenstand in seinem Vortrag erörtert, dem jeder von uns sein aufmerksamstes Interesse zuwenden sollte. Ich möchte anfragen, ob der Vortragende bezüglich der Reinigung industrieller Abwässer in biologisehen Tropf- und Füllkörpern über eigene Erfahrungen verfügt. Lassen sich chlorhaltige Abwässer auf Tropfkörpern überhaupt biologisch nachreinigen? Kleinwesen wirken bei derartigen Abwäsern doch wohl kaum mit.

Dr. Ha upt: Bleichereiabwässer oder überhaupt solche $\mathrm{Abwässer,} \mathrm{welche} \mathrm{freies} \mathrm{Chlor}$ ursprünglich enthalten, lassen sich auf Tropfkörpern biologisch nachreinigen; das Chlor bindet sich bereits bei dem Zusammenleiten mit den alkalisehen und an gelösten organischen Stoffen sehr reichen Kocherlaugen, welche regelmäßig beim Bleichereibetriebo anfallen, zum größßten Teil an die organisehe Substanz dieser Langen. Falls das durch Absetzenlassen genügend vorgereinigte Abwasser noch freies Chlor enthält, verschwindet dieses alsbald bei der Nachreinigung auf biologischen Tropfkörpern, deren Abflüsse sich regelmäßig als ehlorfrei erweisen. Eine möglichste Durchlüftung des Abwassers, welche statt durch Tropfkörper, auch durch eine Art Gradierwerk aus Reisigbündeln, über welche das Wasser im Regenfall geschickt wird, erfolgen kann, ist eine Vorbedingung für den Erfolg. Die Abwässer ans Bleichereien, welche bei ihrem Betrieb vom Rohmaterial (Flachs oder Baumwolle) ausgehen, sind wegen des größeren Gehaltes der Laugen an organischer Substanz schwieriger zu reinigen als die solcher Betriebe, welche nur halbfertiges Material (Garnbleiche, Stückbleiche) verarbeiten. Bai ersteren Betrieben ist das abermalige Absetzenlassen des bereits gelüfteten Abwassers nötig und dann abermalige Belüftung. Für die Nachreinigung ist dann noch Landbehandlung dringend erwünscht. Es handelt sich um Mikroorganismen, welche anscheinend halophytisch sind, und in der an Kochsalz und chlorsauren Salzen reichen Flüssigkeit leben können. Man kann wenigstens, nachdem das freie Chlor nach einmaliger Oxydation der $\mathrm{Abwässer}$ nahezu verschwunden ist, in den Abläufen der zweiten Oxydation, welche noch immer viel organische Substanzen auf- 
weisen, spezifische Organismen, welche anscheinend symbiotisch leben, nämlich eine Oscillatorie und ein sehr großes Bakterium regelmäßig in großen Massen beobachten. Vorbedingung für das Gedeihen dieser die Selbstreinigung offenbar fördernden Organismen ist freilich, da gesamten Abwässer des Betriebes zweeks Vorreinigang zusammengeleitet und der Ruhe überlassen werden.

Dr. Tillmans richtet an den Herrn Referenten die Anfrage, ob er Erfahrungen uber die biologische Reinigung von Gerbereiabwasser habe bezw. ob $\mathrm{ibm}$ biologische Kläranlagen, die Gerbereiabwasser reinigen, bekannt seien.

Dr. Ha upt verneint.

Dr. Tillmans: Die vom Herrn Referenten angeführte Reinigungsmöglichkeit chlorhaltiger Abwässer auf biologischen Körpexn erkläre ich mir so, daßs sich beim Sedimentierprozek das freie Chlor ähnlich, wie es bei der neuerdings vielfach verwendeten Chlorsterilisierang von Trinkwasser ja nachgewiesen ist, an die organischen Stoffe des Abwassers bindet. Die biologischen Körper würden also gar kein freies Chlor erhalten, sodaß eine Schädigung der Körper durch dis chlorhaltigen Abwässer, welche man zunächst erwarten mübte, nicht erfolgt. Die Bestimmung des Sestons nach Kolkwitz hat auch mir bei Flufwasseruntersuchungen ausgezeichnete Dienste geleistet. Insbesondere ist die schnelle Orientierangsmöglichkeit über: Verunreinigungen des Wassers an bestimmten Stellen gegenüber der quantitativen Bestimmung der suspendierten Staffe im Laboratorium hervorzuheben. Einen Einfluf́ fauler Abwässer erkennt man am abgesetzten Seston meist sofort an der dunkleren Fürbung.

Dr. Haupt: Herr Dr. Tillmans erwähnt, daßs die Bestimmung der Sauerstoffzehrung und die Bestimmung des absiebbaren Planktons für die Feststellung des Reinheitsgrades der Flüsse von gröfter Wiehtigkeit seien. Ich kann ihm nur zustimmen, bemerke aber, daß für die Untersuchung der $\mathrm{Ab}$ ässer beide Bestimmungsmethoden nicht oder kaum in Frage kommen, während ich sie gleichfalls hei Flufuntersuchungen nur-empfehlen kann.

Dr. Riechen: Wenn ich Sie recht verstanden habe, sagten Sie, daf die sog. EmscherBrunnen eine Abscheidung der Schwebestoffe bis zu 95--98\% bewirkten. Line derartig weitgehende Klärwirkung halte ich überhaupt für ausgeschlossen; sio trifft auch, soweit ich unterrichtet bin, für die Emscher-Brunnen nicht $z a$, da sie hinsichtlich der Klïrwirkung vor anderen Absatzbecken nichts voraus haben, sondern infolge ihrer besonderen Bauart in erster Linio zur Beseitigung des sich absetzenden Schlammes dienen.

Dr. Haupt: Es ist eine durch die Praxis der Fmscher-Genossenschaft bewiesene Tatsache, daf durch die Emscher-Brunnen, falls keine Überlastung eintritt, 95-98\% der absetzbaren Schwebestoffe - d. h. die sich innerhalb zweier Stunden freiwillig ausscheidenden Schwebestoffe - ausgeschieden werden.

Dr. Grosse-Bohle: Wie verhält es sich mit der Reinigung der Molkereiabwässer?

Dr. Haupt: Jedenfalls lassen sich Molkereiabwässer nicht ohne vorherige Abstumpfung biologisch reinigen. Auch dann bleibt das Reinigungsverfahren im Erfolg zweifelhaft, wenn es nicht im mehrstufigen Betriebe durchgeführt wird. Demgegenüber hat sich in der Praxis die Verrieselung des mit Kalk vorbehandelten Abwassers über größere Landfächen glänzend bewährt.

Der Vorsitzende: Ich danke nunmehr Herrn Dr. Haupt nochmals für seinen interessanten und anregenden Vortrag und die Erläuterungen, die er uns in der Diskussion soeben gegeben hat. - Jedenfalls wäre es erwünscht, wenn diesem Gegenstande auf unseren Versammlungen eine größere Aufmerksamkeit als bisher geschenkt würde.

Unsere Tagesordnung ist damit erschöpft. Wird das Wort noch gewünscht? Das ist nicht der Fall. Ich spreche den Herren für ihre lebhafte Anteilnahme an unserer Verhandlnng, insbesondere den Herren Vortragenden für ihre Mühe, die sie sich gegeben haben, unsere Versammlung zu einer anregenden und lehrreichen zu machen, herzlichen Dank aus. Mit dem Wunsche, auf ein frohes Wiedersehen in Jahresfrist in Koblenz zur 13. Hauptversammlung unseres Vereins, schließe ich hiermit die Sitzung.

Dr. Grünhut: Meine sebr verehrten Herren! Am Schlusse dieser Versammlung möchten wir unserem verehrten Herrn Vorsitzenden unseren Dank für die Leitung der Geschäfte aussprechen. Es ist nicht das erstemal, daß wir ihn an der Spitze der Leitung unserer Versammlung sehen. Er hat in den letzten Jahren oft den ersten Vorsitzenden vertreten. Aber wir haben ihn heute $\mathrm{zu}$ erstenmale als ersten Vorsitzenden die Versammlung leiten sehen. Wenn wir zurückblicken auf das, was uns diese Versammlung in Breslau gebracht hat, so müssen wir bekennen, daß 
wir alles gefunden haben, was wir erwartet haben: Wir haben den persönlichen Anschluf aneinander erneuert, wir haben neuen Anschluß gefunden, und das alles ist das Verdienst seiner Liebenswürdigkeit und straffen Leitung der Verhandlung.

Ich bitte Sie, dem Dank, den wir empfinden, Ausdruck zu verleihen, indem Sie mit mir einstimmen in den Ruf: Unser erster Vorsitzender, er lebe hoch, hoeb, hoch!

$$
\text { (Schluß der Sitzung } 2^{1 / 2} \text { Uhr nachmittags). }
$$

\section{Berichte über die Tätigkeit von Untersuchungsämtern etc.}

Bericht über die Tätigkeit des Öffentlichen Nahrungsmittel-Untersnchnngsamtes zn Koblenz für das Jahr 1912. Erstattet vom Vorsteher des Amtes, Dr. Petri. 48 S. $8^{\circ}$. Die Zahl der Untersuchungen betrug 4254, wovon 4099 auf Lebensmittel und Gebrauchsgegenstände, 19 bygienische, 74 technische und 62 gerichtliche Gegenstände entfallen. Es wurden u. a. untersucht: 18 Fleisch, 334 Wurst, 524 Milch, 18 Käse, 761 Speisefette and Ölo, $126 \mathrm{M}$ üllereierzeugnisse usw., 164 Gewürze, 109 Essig, 28 Zucker, 108 Fruchtsäfte, Limonaden, Marmeladen usw., 58 Gemüse und Fruchtdauerwaren, 21 Honig, 124 Spirituosen, 50 Wasser, 1389 Wein, 9 Bier, 5 alkobolfreie Getränke, 76 Kaffee und Ersatzstoffe, 6 Tee, 53 Kakaowaren, 2 Konservierungsmittel, 24 Hefe, 5 Tabak, 87 Gebrauchsgegenstände usw. - Fle is ch: Eine Sendang Auslandsrindfleisch enthielt Borsäure. - Wurst: 26 Leberwürste enthielten Mehl bis $10,9 \%$; eine Leberwurst mit $70 \%$ Wasser enthielt $0,93 \%$ Borsäure. Bei 36 beanstandeten Fleischw ürsten ging der Mehlgehalt bis 8,5 und der Wassergehalt bis $69,1 \%$, bei 15 sonstigen Würsten bis 9,2 bezw. 76,5\%. - M il ch: Etwa $1 / 5$ aller Proben war zu beanstanden, davon 37 wegen Wässerung. Der mittlere Fettgehalt war 3,07\%, - Butter: 29 Proben enthielten zuviel Wasser bis $34 \%$. 2 Proben waren mit Margarine verfälscht. Backwaren: 4 Proben Buttergebäck waren mit Margarine hergestellt. - Issig: Neben Zusätzen von Kochsalz war fast die Hälfte der untersuchten Weinessigproben mit Holzessig verfälscht. - Obstkraut: Die Beanstandungen betrafen meist Zusatz von Stärkesirup bis $35 \%$. - Marmeladen: Etwa $1 / 3$ der Proben mufste beanstandet werden; 1 Apfelgelee enthielt $85 \%$ Stärkesirnp. Die Verwendung von Apfeltrestern hat erheblich zugenommen. - Honig: Einmal wurde Rübenkraut untergeschoben. - Wein: Ein Auslandswein wurde wegen Zusatzes von Weinsäure von der Einfuhr zurückgewiesen. Die Beanstandungen der Inlandsweine wegen Überstreckung sind in stetem Rückgang begriffen, dagegen zeigte der 1912 er eine auffallende Zunahme der Überzuckerung. Obstwein: Apfelwein war unter Verwendung von Trabentrestern hergestellt worden. - Kaffee: Die Menge der abwaschbaren Stoffe ging bis 9,2, der Wassergehalt bis $6,82 \%$.

C. $M a i$

Bericht über die Tätigkeit des öfentlichen Nahrnngsmittel-UntersnehmngsAmtes für das Fürstentum Schwarzburg-Sondershausen während der Geschäftsjahre 1911/12 und 1912/13. Erstattet von Medizinalassessor Hofrat Dr. B. Wagner. Vorstand des Untersuchungsamtes, und Dr. Erich Ewers, Vorstand der Abteilung für Nahrungsmittelchemie. Sondershausen 1913. 34 S. $8^{\circ}$. - Die Zahl der Untersuchungen betrag $12743-16055$, wovon $3775-3899$ auf Lebensmittel und Gebrauchsgegenstände, 32-31 hygienische, 24-32 agrikulturchemische, 8904-12088 technische und 8-5 gerichtliche Gegenstände entfallen und von denen 9360-12370 von Privaten, die übrigen von Behörden veranlakt waren. Zu Beanstandungen gaben 588-760 Proben Anlaßi. Es wurden u. a. untersucht: 379-306 Fleisehwaren (45-53 beanstandet), 341-358 Milch $(61-51)$, 3-2 Rahm, 50-35 Käse, 139-170 Speisefette and Öle (24-56), 322-345 Müllereierzengnisse, Back- und Teigwaren (57-149), 169-151 Gewürze (13-38), 139-99 Essig (29-21), 126-92 Zuckerwaren (7-17), 105-126 Fruchtsäfte, Marmeladen, Limonaden usw. (15-17), 88-119 Obst, Gemüse, Dauerwaren (7 -18), 183-130 Spirituosen (11-58), 53-120 Bier und Wein $(1-4), 173-70$ Kaffee, Tee, Kakaowaren $(2-5), 378-195$ Wasser $(95-12)$, 355-619 Gebrauchsgegenstände $(70-128)$ usw. - Fleisch: Vereinzelt wurden Zusătze von Sulfiten oder Borsäure, seltener Benzoesäure zu Hackfleisch beobachtet. - Mileh: Der mittlere Fettgehalt der unbeanstandeten Proben war $3,57 \%$; die fettfreie Trockenmasse lag zwischen 8,023 und 10,426\%. - Honig: Mehrere Proben waren mit Stärkezncker oder Invertzucker verfälscht. - Marzipan: Eine Probe wurde wegen Mehlgehaltes beanstandet. - Limonaden: Eine Probe mufte beanstandet werden, weil das zur Herstellung verwendete Wasser zum menschlichen Genußs ungeeignet war. 